\title{
Water retention in kenaf/polypropylene composites due to repeated immersion and drying conditions
}

\begin{abstract}
Lignocelluloses based natural fibers composites are very prone to water absorption due to $\mathrm{OH}$ functional group within cellulose and hemicelluloses of natural fibers. In this work, the water retention in the kenaf/polypropylene (kenaf /PP) composite due to repeated immersion and drying are studied. The composites (40\%, 50\%, 60\% and 70\% fiber loading) are immersed in the water and then dried in room condition $\left(24^{\circ} \mathrm{C}\right.$ and $48 \%$ humidity) for 4 cycles ( 1 cycle is 10 days of immersion and drying). The parameters are $8 \backslash 2$ (imply 8 days immersion $\backslash 2$ days drying), 6\4, 4\6 and $2 \backslash 8$ per cycle. Continuous immersion (100\% immersion) is used as a reference of water absorption behavior of the composite. The results for $70 \%$ fiber loading under minimum drying days of $8 \backslash 2$, shows that the water retention reduced to $36 \%$ from the water absorbed and further drying only reduced to $31 \%$. When the experiment are repeated for several cycles, $70 \%$ fiber loading composites shows a decreasing pattern in water retention at the second cycle whereas $40 \%$ fiber loading composite showing an increasing pattern. Duration of immersionldrying does play an important role in the amount of water retention in the composite. The water retention of the composites either show an increasing or decreasing pattern depending on kenaf fiber loading and repetition of the immersionldrying for several cycles.
\end{abstract}

Keyword: Absorption; Kenaf; Kenaf/PP composite; Repeated water immersion; Retention 